\title{
Article \\ Econometric Approach to Assessing the Transfer Fees and Values of Professional Football Players
}

\author{
Raffaele Poli *(D), Roger Besson and Loïc Ravenel \\ Centre International d'Etude du Sport, University of Neuchatel, 2000 Neuchatel, Switzerland; \\ roger.besson@unine.ch (R.B.); loic.ravenel@unine.ch (L.R.) \\ * Correspondence: raffaele.poli@unine.ch
}

Citation: Poli, Raffaele, Roger Besson, and Loïc Ravenel. 2022. Econometric Approach to Assessing the Transfer Fees and Values of Professional Football Players. Economies 10: 4 https://doi.org/10.3390/ economies10010004

Received: 2 November 2021

Accepted: 21 December 2021

Published: 23 December 2021

Publisher's Note: MDPI stays neutral with regard to jurisdictional claims in published maps and institutional affiliations.

Copyright: (c) 2021 by the authors. Licensee MDPI, Basel, Switzerland. This article is an open access article distributed under the terms and conditions of the Creative Commons Attribution (CC BY) license (https:// creativecommons.org/licenses/by/ $4.0 /)$.

\begin{abstract}
Billions of euros are invested every year by professional football clubs for the recruitment of players. How do market actors decide prices? This paper presents an econometric model unveiling the key factors coming into play in determining fees on the transfer market for professional football (soccer) players. The statistical technique used to build the model is multiple linear regression (MLR), with fees paid by clubs as an independent variable. The sample comprises over 2000 transactions of players transferred for money from clubs in the five major European leagues during the period stretching from July 2012 to November 2021. This paper notably highlights the importance of taking into consideration the remaining duration of contracts binding players with the club to which they belong, a factor often neglected in the existing literature. It also shows that a statistical model can explain over $80 \%$ of the differences in the transfer fees paid for players. This paper reveals various applications of the approach developed for the football industry to both assess and predict football players' transfer fees and values: transfer negotiations, club sales or purchases, bank credit, fund raising, financial planning and communication, legal disputes, etc.
\end{abstract}

Keywords: football; soccer; transfer value; transfer fees; econometric model

\section{Introduction}

This paper outlines the approach developed by the authors to assess from an econometric perspective the transfer value of professional football (soccer) players. Inspired by FIFA's (Fédération Internationale Football Association) wording (FIFA 2021), as well as by Herm et al. (2014), Müller et al. (2017) and Velema's (2018) papers, transfer value is defined as the fee that an engaging team is willing to agree with the releasing team as compensation for breaching the contract of a player with respect to the transfer fees paid in the past for footballers with similar characteristics.

Transfer fees are agreed by market actors on a free basis, following negotiations that can last several weeks or even months. These negotiations include the representatives of both the engaging and releasing teams (primarily club owners, CEOs and sports directors), as well as, using again FIFA's wording (FIFA 2015), football intermediaries, more commonly known as football agents (Poli 2009). The latter may represent both the player and the clubs involved and, in the latter case, may be entitled to a share of the transfer fee negotiated.

Complementing the pioneering work in this area dating back almost 30 years (Carmichael and Thomas 1993; Carmichael et al. 1999; Dobson and Gerrard 1999), this paper highlights that the football transfer market follows specific logics that can to a large extent be modelled. It adds value to previous research in this field by relying on an unprecedentedly large sample of fee-paying transactions with full information available (notably concerning players' contract duration) covering all the five major football markets (England, Spain, Italy, Germany and France) over an extended period (almost ten years).

This paper also has the merit to include in the regression analysis explaining transfer fees paid by clubs a key variable most often neglected so far: players' contract duration. In this regard, Dobson and Gerrard (1999) mentioned that "from the 1996-1997 season onward, 
the expiration date of a player's contract is likely to have become a key determinant of a transfer fee, especially for players within 12 months of becoming free agents" (p. 267).

In addition, while only a minority of the transfer fee figures used are data disclosed by clubs, contrary to most articles dealing with this topic as detailed in the methodological chapter, this paper does not solely rely on a single publicly available data source, the German website Transfermarkt. The dataset was instead built by cross-checking a large array of sources, which allows us to be even more confident of the fact that the eventual inaccuracies in the recording of transfer amounts paid by clubs do not introduce significant bias in the regression results.

This paper reviews the existing literature on the topic of transfer fees, describes how the database from which the modelling of football players' transfer values was built, outlines the variables included in the econometric model developed for this purpose and assesses the robustness and explanatory power of the latter from a statistical perspective, while also showing how it can be applied to evaluate former fee-paying transfers and estimate current transfer values. The discussion chapter addresses from a critical perspective some limitations of the approach and presents its main applications.

\section{Methodology}

\subsection{Literature}

When dealing with the topic of transfer fees, both the media and academics have most often focused on the concept of players' market value (Coates and Parshakov 2021; He et al. 2015; Herm et al. 2014; Kirschstein and Liebscher 2019; Majewski 2016; Müller et al. 2017; Prockl and Frick 2018; Romann et al. 2021; Serna Rodríguez et al. 2018; Singh and Lamba 2019; Velema 2018). However, we consider that the concept of a players' transfer value is more appropriate, as it clearly refers to transfer fees as described above, while the concept of market value is more ambiguous. It can indeed also be used in reference to players salary, image rights, notoriety, etc.

A perfect example of the conceptual confusion around the term of market value is provided by Serna Rodríguez et al. (2018). These authors outline that "the literature uses the "market values" as a proxy for player wages or transfer fees" (p. 7). The same authors recognize that "there are conceptual differences between market values and transfer fees" (p. 7), but, quoting He et al. (2015), as also done by Müller et al. (2017, p. 612), they conclude that "they are comparable" (p. 7). In addition, by quoting Wicker and Weimar (2017), they indicate that "market values of soccer players are commonly used as wage proxies" (p. 2).

In reality, transfer fees and wages are not always aligned. On the contrary, they can in many cases be largely divergent. This is notably the case for out-of-contract footballers, who, since the "Bosman" ruling of the European Court of Justice in 1995, can sign with another team without the payment of any transfer indemnity (Antonioni and Cubbin 2000). This does not prevent the best performing out-of-contract players from having had very high wages with their former clubs, nor from obtaining very high ones with their new team. The fact that the latter does not have to pay a fee to sign them is often a strong argument for sought-after out-of-contract footballers to negotiate higher salaries. Moreover, young players generally have lower wages than more experienced ones, but, all other things being equal, as further discussed, the fees paid for their transfers are higher.

Some authors (Felipe et al. 2020; Kirschstein and Liebscher 2019; Müller et al. 2017) added another layer to the widespread conceptual confusion by building models to determine "market values" as published by the German reference website Transfermarkt, and treating them as if they were transfer values as defined above, while, in reality, they are not. Indeed, as already mentioned, transfer fees are to be paid only for players with a valid contract to compensate its breach, while Transfermarkt also attributes "market values" to out-of-contract footballers who are free to sign for another team with no transfer indemnity payment. 
In this regard, Coates and Parshakov demonstrated that crowd-sourced Transfermarkt "market values" tend to underestimate actual fees paid for players, and, as such, they "are a biased predictor of the true fee value" (p. 11), while adding that "for those who use transfer fees as a proxy for actual fees or player salaries, our findings are a warning. Our results do not say that Transfermarkt should not be used in regression analysis of football labor markets, but they do indicate that caution should be exercised when doing so" (p. 11).

The first scientific attempts to model actual transfer fees date back almost thirty years (Carmichael and Thomas 1993). Since then, other authors developed have econometric models to estimate players' transfer fees (Carmichael et al. 1999; Coates and Parshakov 2021; Dobson and Gerrard 1999; Dobson et al. 2000; Garcia del Barrio and Pujol 2021; Majewski 2016; Ruijg and Ophem 2015). These authors notably highlighted the significant impact on the transfer fees paid by football teams of variables such as the players' age, position, international status, goals scored, employment, media exposure, as well as the buying club's characteristics (notably the league it belongs to).

Among these authors, only Garcia del Barrio and Pujol (2021) and Coates and Parshakov (2021) included the contractual situation of the footballers transferred into their models. They were able to do so only for a reduced sample of the transactions for which they recovered information on transfer fees. With regard to contracts, Garcia del Barrio and Pujol (2021) mentioned that "a penalty in terms of economic value is found for players whose contract (...) is about to expire within a year. On the contrary, the empirical analysis indicates that the value of players whose current contract will last three or more years is associated to an economic premium" (p. 804).

As also highlighted by Dobson and Gerrard (1999) and further developed, a possible explanation for the recurrent omission of players' contract duration is that the gathering of this variable necessitates a tedious and time-consuming job. However, as we will also point out below, contract length is a key variable taken into account by market actors during transfer negotiations in order to determine prices and should thus be included in any statistical model aiming at assessing football players' transfer fees and values.

\subsection{Database}

While very popular and, as such, scrutinized by the media worldwide, from the perspective of transfer fees and economic data related to players more generally, football suffers from a lack of transparency. Official figures regarding transfer fees are only published by clubs listed on the stock market (Juventus, Olympique Lyonnais, AS Roma, SL Benfica, Sporting CP, etc.), but these represent just a small minority of all clubs. Nevertheless, the extensive media coverage of player transfer operations and a fine cross-checking of all sources available allows us to determine with an acceptable level of accuracy the amounts of fees invested by clubs to sign new players.

By cross-checking media sources, priority was given to the more established sources, those whose journalists are best connected to club officials and agents, and have proved in the past to be more reliable. Among these sources, we can notably quote traditional newspapers such as Kicker in Germany, the Guardian or the BBC in England, Gazzetta dello Sport in Italy, France Football and L'Équipe in France, as well as Diario AS in Spain. In addition, detailed and reliable information on transactions is also provided by regional media, specialized websites and well-connected journalists (tuttomercatoweb.com, gianlucadimarzio.com, $@$ FabrizioRomano, etc.).

These sources allow us to access more detailed information on transactions with respect to that available on the German reference website Transfermarkt. This is notably true concerning conditional payments (i.e., additional payments for releasing teams if new recruits or engaging teams reach certain sporting objectives) and sell-on fees (i.e., most often a percentage on the future fee to which the releasing team is entitled in case of further transfer). This is of particular importance for the accuracy and comparability of the transfer amounts data collected. Indeed, the use of conditional payments and sell-on 
fees has increased year by year, and henceforth concerns a majority of fee-paying transfers (FIFA TMS 2020; Poli et al. 2020).

This fine cross-checking work allows us not only to reach a good level of accuracy, but also to exclude from the sample some transfers for which equally reliable and detailed sources present quite different figures. However, for the five major European leagues, including transfers for which no information about eventual fees is publicly available, only about $10 \%$ of total fee-paying transfer operations were removed from the sample because of data which were too divergent or missing information.

After each transfer window, the publication by FIFA TMS of the aggregate transfer fee figures per league for international transactions allows us to compare totals. While FIFA TMS only covers transfers between clubs located in different national associations, this comparison suggests that the fees disclosed by the media for international transfers are generally under-estimated, being on average about $10 \%$ less than the actual fees, probably because of the widespread existence of conditional payments, which are not always known or fully reported by publicly available sources.

The consulting of club balance sheets indicating players' residual transfer values, details published within the framework of legal disputes, as well as insider information to which we can gain access through our contacts in the football industry or the mandates undertaken for market actors (clubs, agents, legal firms, etc.), which also allow us to confirm or correct transfer fee figures. All these procedures make it possible to assert that the level of accuracy of the transfer fee data collected, although not perfect, is at least satisfactory to build robust econometric models without significant bias.

While not as tedious as that needed for transfer fees, the data collection work regarding contracts is also time-consuming. The cross-checking of several sources is indeed also essential for contracts. On this level, a specific element to be carefully monitored is the verification of the existence of extension options in favor of the employer clubs. It is indeed quite common that player contracts can be automatically extended by clubs by one or more year without conditions or, in other cases, as soon as players or clubs themselves reach certain sporting objectives (number of matches played, promotion, etc.).

The other variables included in the econometric model developed can be collected more easily as they are available as such in various public sources, including club and league websites (minutes played, team results, etc.). More specific performance data such as passes, dribbles, interceptions, etc., were produced and provided to us by specialized companies such as Opta (StatsPerform) or InStat, with which we partner. In addition, different websites, among which those of the major competition organizers are included, make the players' performance data collected by specialized companies increasingly available to the general public.

\subsection{Variables}

The variables included in the econometric model developed to assess the transfer fees and estimate the transfer values of professional football players can be categorized into three groups-the variables relating to clubs, those relating to players, as well as a contextual variable: the season during which the transfer took place. This latter variable allows us to take into consideration the evolution of prices, all other things being equal, in a strongly inflationary environment.

The variables relative to clubs refer to the level of teams where footballers played during the two years preceding their transfer from both a sporting and financial perspective. From the sporting point of view, the teams' level is calculated by considering results obtained at the domestic league level and the division played (i.e., for England, the Premier League, Championship, League One, League Two, etc.). On an international level, leagues are ranked according to results achieved by their representatives in international competitions (UEFA Champions League or Europa League, CONMEBOL Copa Libertadores or Copa Sudamericana, CAF Champions League or Confederation Cup, etc.). 
From the economic point of view, the clubs' level is calculated by taking into account their transfer fee expenditure over the five seasons preceding the transfer window during which the deal took place. The equation also includes the total investment into the acquisition of players at the level of the league to which the clubs belong. This is notably helpful to anticipate the new economic force of freshly relegated or promoted clubs.

The variables relative to players are more numerous. They include the length of contract remaining with the owner club (as stressed above, the transfer fee is de facto a compensation for breaching a player's contract), players' age, career progression, position (goalkeepers, center backs, full backs, midfielders, forwards), as well as their performances in the different competitions played for both clubs and national teams (minutes, goals, assists, dribbles and passes).

To reiterate, the econometric model developed by the authors to explain transfer fees includes the following variables.

- The variable [contract] refers to the remaining contract duration (number of days) of the player at the owner club.

- The variable [age] refers to the age at transfer (the younger the better).

- The variables [exp_gk], [exp_cb], [exp_fb], [exp_md] and [exp_of] refer to the overall experience (minutes in official senior games) of players, according to their position, during the 24 months preceding the transfer, weighted by the sporting level of the clubs and competitions in which the games were played.

- $\quad$ The variable ([dynpro]) refers to players whose recent experience level (last 12 months) progressed with respect to the 12 previous months and that, by considering the economic and sporting levels of their club of employment, still have a margin to pursue an upward career path in the following months.

- $\quad$ The variable ([dynpro]) refers to players whose recent experience level (last 12 months) decreased with respect to the 12 previous months and that, by considering the economic and sporting levels of their club of employment, still have a margin to pursue a downward career path in the following months.

- $\quad$ The variable [goal] refers to the number of goals scored during the 24 months preceding the transfer weighted by the sporting level of the leagues and competitions in which they were scored.

- The variable [assist] refers to the number of successful assists achieved during the 12 months preceding the transfer weighted by the sporting level of the leagues and competitions in which they were made.

- $\quad$ The variable [pass] refers to the number of accurate passes achieved per minute played (at least $270^{\prime}$ ) during the 12 months preceding the transfer weighted by the sporting level of the leagues and competitions in which they were made.

- The variable [dribble] refers to the number of successful dribbles achieved per minute played (at least 270') during the 12 months preceding the transfer weighted by the sporting level of the leagues and competitions in which they were made.

- The variable [ateam] refers to players who have participated in national A-team matches since the start of their career, weighted by the level of the national team represented, calculated by considering the average experience of players capped.

- The variable [buyclub] refers to the economic level of the recruiting club.

- The variable [inflat] is the average value of the 100 largest transfer fees completed on a global level during each of the last four transfer windows, which allows us to take inflation (or deflation) into account.

\section{Results}

The econometric model presented was built from 2045 fee-paying transfers that occurred between July 2012 and November 2021 concerning players belonging to teams from the five major European leagues: the English Premier League, the Spanish La Liga, the Italian Serie A, the German Bundesliga and the French Ligue 1. From a monetary volume perspective, transfers concerning these leagues represent about two-thirds of total 
transactions (FIFA TMS 2020; Poli et al. 2020). In addition, the extensive media coverage concerning these competitions allowed us to gather detailed and reliable information on both transfer fees and contract duration.

The dependent variable of the model, transfer fees, includes add-ons (conditional payments) and sell-ons (the fee paid for a portion of transfer rights is projected as if the club acquired the whole rights, i.e., EUR $4 \mathrm{M}$ if a club paid EUR $2 \mathrm{M}$ for $50 \%$ of the rights). Transfers concluded by means of a buy-out clause fixed before the transaction took place were removed from the sample (i.e., the EUR 222M record fee paid by Paris St-Germain for the signing of Neymar Júnior). This is also notably the case for players signed on a permanent basis after a period on loan for a fee negotiated at the start of the loan period, irrespective of the player's performance at the club to which he was loaned.

The fees for transfers included in the sample stretch between $€ 0.1 \mathrm{M}$ (for five players) to a maximum of $€ 180 \mathrm{M}$ in the case of Kylian Mbappé's 2017 transfer from AS Monaco to Paris St-Germain. In total, only ten values are above the EUR 100M threshold as illustrated in Table 1. Figure 1 shows that the statistical distribution of fees is very asymmetrical, and two thirds of observations are below EUR 10M, with a median value of $€ 5.3 \mathrm{M}$. The logarithmic transformation of the values provides a distribution that is much more suitable for linear regression analysis.

Table 1. Most expensive transfers in the sample.

\begin{tabular}{ccccc}
\hline Year & Player & From & To & EUR Million \\
\hline 2017 & Kylian Mbappé & AS Monaco & Paris St-Germain & 180 \\
2018 & Philippe Coutinho & Liverpool FC & FC Barcelona & 160 \\
2017 & Ousmane Dembélé & Borussia Dortmund & FC Barcelona & 147 \\
2019 & Antoine Griezmann & Atlético Madrid & FC Barcelona & 135 \\
2019 & Eden Hazard & Chelsea FC & Real Madrid & 130 \\
2021 & Romelu Lukaku & Internazionale FC & Chelsea FC & 115 \\
2016 & Paul Pogba & Juventus FC & Manchester United & 110 \\
2018 & Cristiano Ronaldo & Real Madrid & Juventus FC & 105 \\
2017 & Romelu Lukaku & Everton FC & Manchester United & 102 \\
2013 & Gareth Bale & Tottenham Hotspur & Real Madrid & 100 \\
\hline
\end{tabular}

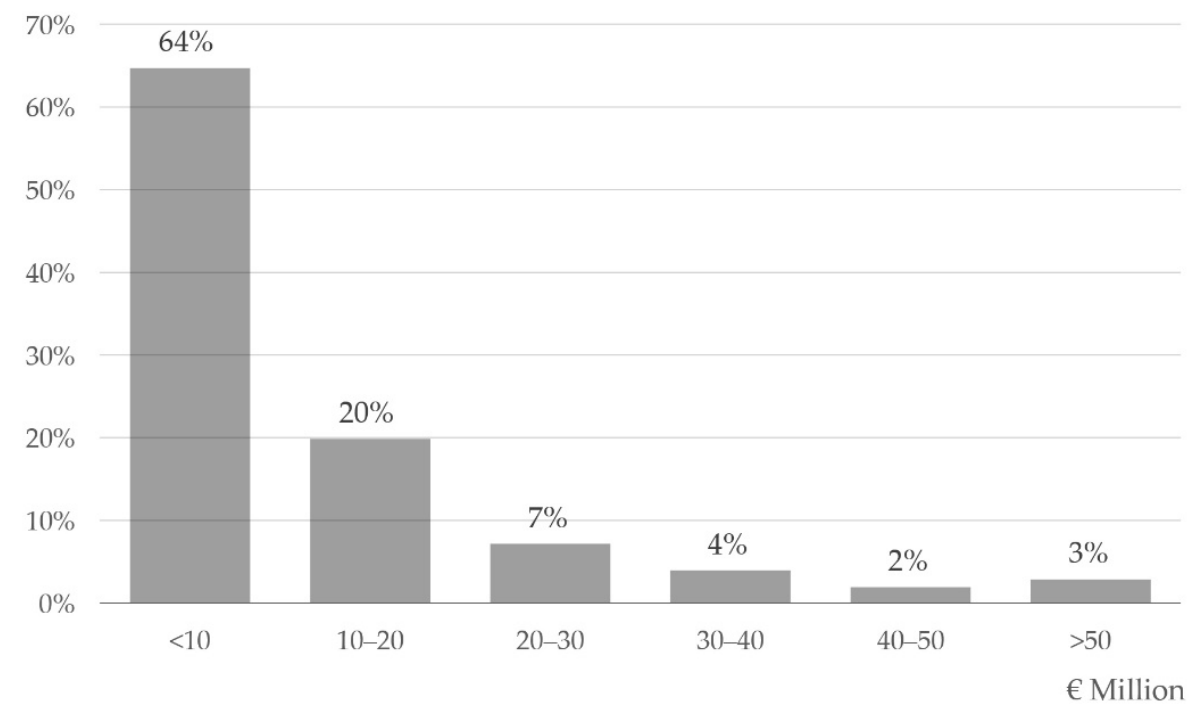

Figure 1. Distribution of transfers in the sample per price category ( $€$ million).

The model selected is multiple linear regression (MLR). This statistical technique, using several explanatory variables to predict the outcome of a dependent one, not only perfectly fits our purpose, i.e., explaining transfer fees or estimating transfer values prior to transfers, but is also easily applicable and understandable for people without any deep 
statistical background. The latter criterion is of particular importance within the framework of the mandates carried out by the authors for football stakeholders. In addition, the other models and approaches tested, notably neural networks, did not provide better results.

In the model obtained, as illustrated in Table 2, all variables selected are significant. Contract length, age and experience are the most important player-related variables. All other things being equal, an additional year on the contract for a player with a remaining contract duration of two years has a positive impact of $22 \%$ on the fees paid by recruiting clubs. Similarly, all other things being constant, one year less in age has a positive impact of $12 \%$. For example, the estimated price for Cristiano Ronaldo (EUR 79.6M) in the summer 2018 would have reached EUR 89.3M if the Portuguese had been 32.5 years old instead of 33.5 at the moment of the transfer.

Table 2. Multiple linear regression model to assess transfer fees.

\begin{tabular}{|c|c|c|c|c|c|}
\hline \multicolumn{2}{|c|}{ Number of obs } & 2045 & & & \\
\hline \multicolumn{2}{|c|}{$\mathrm{F}(16,2028)$} & 747.51 & & & \\
\hline \multicolumn{2}{|c|}{ Prob > F } & 0 & & & \\
\hline \multicolumn{2}{|c|}{ R-squared } & $85.5 \%$ & & & \\
\hline \multicolumn{2}{|c|}{ Adj R-squared } & $85.4 \%$ & & & \\
\hline \multicolumn{2}{|c|}{ Root MSE } & 0.220 & & & \\
\hline Source & SS & df & MS & & \\
\hline Model & 580.29 & 16 & 36.27 & & \\
\hline Residual & 98.40 & 2028 & 0.05 & & \\
\hline Total & 678.69 & 2044 & 0.33 & & \\
\hline variable & b-coeff. & stand. beta & $\mathbf{t}$ & $p>\mathbf{t}$ & sign \\
\hline contract & 0.494 & 0.214 & 23.1 & 0.000 & $* * *$ \\
\hline age & -0.050 & -0.306 & -28.4 & 0.000 & $* * *$ \\
\hline exp_gk & 0.558 & 0.407 & 28.1 & 0.000 & $* * *$ \\
\hline exp_cb & 0.512 & 0.749 & 28.4 & 0.000 & $* * *$ \\
\hline exp_fb & 0.450 & 0.606 & 25.4 & 0.000 & $* * *$ \\
\hline exp_md & 0.488 & 0.793 & 25.8 & 0.000 & $* * *$ \\
\hline exp_of & 0.478 & 0.934 & 24.2 & 0.000 & $* * *$ \\
\hline dynpro & 0.304 & 0.079 & 7.8 & 0.000 & $* * *$ \\
\hline dynreg & 0.145 & 0.028 & 3.0 & 0.003 & $* *$ \\
\hline goal & 0.165 & 0.217 & 13.0 & 0.000 & $* * *$ \\
\hline assist & 0.062 & 0.043 & 3.7 & 0.000 & $* * *$ \\
\hline pass & 0.002 & 0.049 & 3.5 & 0.000 & $* * *$ \\
\hline dribble & 0.032 & 0.054 & 4.5 & 0.000 & $* * *$ \\
\hline ateam & 0.001 & 0.052 & 5.5 & 0.000 & $* * *$ \\
\hline buyclub & 1.010 & 0.287 & 25.7 & 0.000 & $* * *$ \\
\hline inflat & 1.184 & 0.279 & 31.7 & 0.000 & $* * *$ \\
\hline _cons & 2.801 & . & 29.6 & 0.000 & $* * *$ \\
\hline
\end{tabular}

The context, linked to inflation and the economic power of the recruiting club, is the other major explanatory element. With regard to inflation, an annual average growth of 9.6\% was recorded between 2012 and 2021. As a consequence, all else being unchanged, the cost of a player went up by $129 \%$ during this period. The financial strength of the recruiting club also has a strong impact on fees. By way of example, the estimated price for Naby Keita (EUR 70.M) in the summer 2018 would have been $25 \%$ lower if the player had been signed by Leicester City instead of Liverpool FC. In the end, the coefficient of determination of the model exceeds $85 \%$ as displayed in Figure 2. 


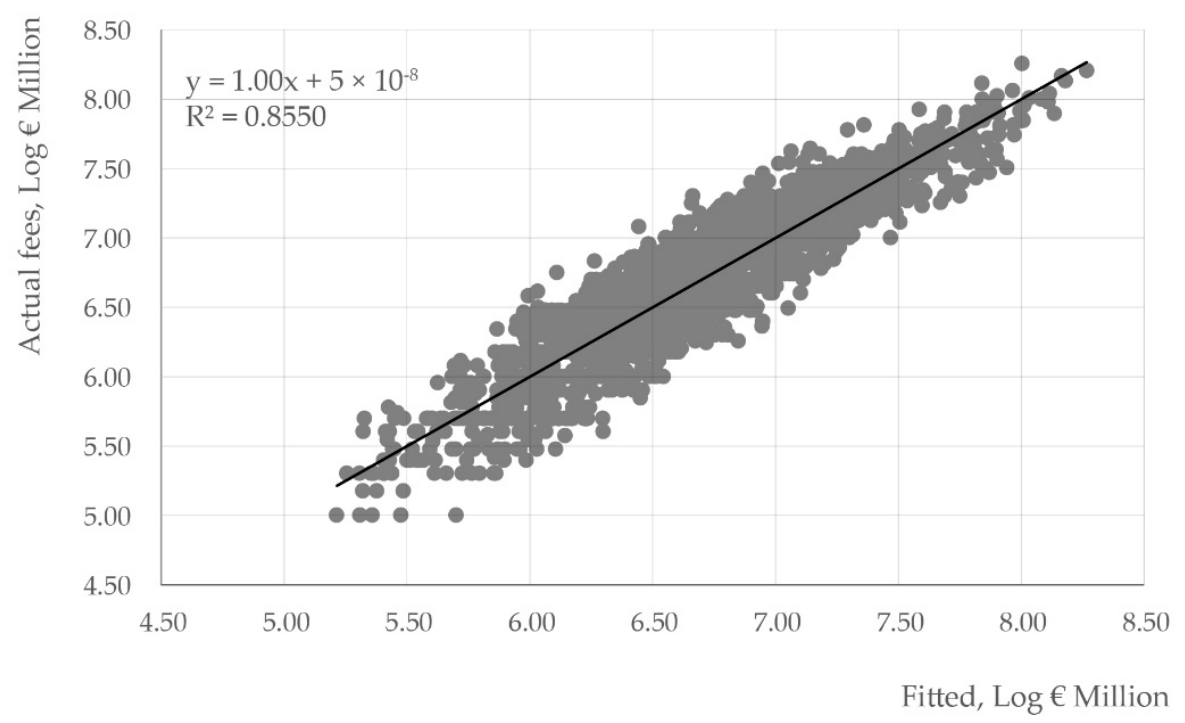

Figure 2. Fitted and actual transfer fees.

A closer look at the main residuals for the transactions included in the sample allows us to highlight various cases where the fees estimated by the econometric model are quite far from actual indemnities paid by recruiting clubs. With regard to two Liverpool FC signings, for example, this comparison shows that the strikers Mario Balotelli (signed in 2014 from AC Milan) and Mohamed Salah (signed in 2017 from AS Roma) were underpaid: $-64 \%$ and $-23 \%$, respectively. In the former case, the gap can be explained by the disciplinary concerns surrounding the player, while in the second, AS Roma's urgent need for cash to comply with UEFA Financial Fair Play (FFP) rules can explain the difference.

Table 3 provides a more general picture of the average gaps between actual and estimated fees for the six wealthiest English Premier League clubs. For incoming transfers, Manchester United and Arsenal paid in total about 10\% more than the expected amount to sign players between 2012 and 2021, while Chelsea FC has been particularly skilled in negotiations $(-16 \%)$. With regard to outcoming transfers, Chelsea FC was even more skilled $(+37 \%)$, while Manchester City is in the opposite situation $(-15 \%)$.

Table 3. Gaps between actual and fitted transfer fees for the six wealthiest English clubs.

\begin{tabular}{|c|c|c|c|c|c|c|}
\hline & \multicolumn{3}{|c|}{ Outcoming Transfer Gaps } & \multicolumn{3}{|c|}{ Incoming Transfer Gaps } \\
\hline & Number & $\begin{array}{c}\text { Average } \\
\text { (€ Million) }\end{array}$ & $\%$ & Number & $\begin{array}{c}\text { Average } \\
\text { (€ Million) }\end{array}$ & $\%$ \\
\hline Arsenal FC & 16 & -1.9 & $-10.2 \%$ & 23 & +2.6 & $+8.7 \%$ \\
\hline Chelsea FC & 18 & +9.3 & $+36.9 \%$ & 29 & -7.2 & $-16.2 \%$ \\
\hline Liverpool FC & 23 & -2.9 & $-13.7 \%$ & 26 & -0.2 & $-0.8 \%$ \\
\hline Manchester City & 16 & -2.8 & $-15.3 \%$ & 23 & -3.0 & $-7.4 \%$ \\
\hline Manchester United & 24 & -0.6 & $-3.8 \%$ & 20 & +3.7 & $+7.4 \%$ \\
\hline Tottenham Hotspur & 31 & +2.6 & $+20.0 \%$ & 24 & -1.4 & $-6.0 \%$ \\
\hline
\end{tabular}

An efficient way to test the quality of the model and its predictive power is to apply a cross-validation. For this purpose, the sample was divided into five subgroups of equal size. In each case, a model was created using the transactions in four sub-groups (the training sample) and applied to deals included in the remaining one (the test sample). As illustrated in Table 4, the different models produced are very stable, and their application gives convergent results, particularly in terms of the adjusted coefficient of determination. 
Table 4. Five-fold cross-validation analysis for model to assess transfer fees.

\begin{tabular}{lcccc}
\hline & \multicolumn{2}{c}{ Training Sample } & \multicolumn{2}{c}{ Test Sample } \\
& N & r2_adj & N & r2_adj \\
\hline Cross-validation 1 & 1636 & $84.7 \%$ & 409 & $87.5 \%$ \\
Cross-validation 2 & 1636 & $85.4 \%$ & 409 & $85.1 \%$ \\
Cross-validation 3 & 1636 & $85.4 \%$ & 409 & $85.5 \%$ \\
Cross-validation 4 & 1636 & $86.0 \%$ & 409 & $82.8 \%$ \\
Cross-validation 5 & 1636 & $85.4 \%$ & 409 & $85.0 \%$ \\
\hline
\end{tabular}

With regard to heteroscedasticity, Figure 3 relating the residuals to the fitted values does not show particular concerns. However, the White or Breusch-Pagan tests do not allow us to validate the hypothesis of the homoscedasticity of the variance of the residuals. The model slightly over-estimates the fees at the extreme ends of the estimated price categories, while it tends to under-estimate those in the middle of the distribution. The average difference for the bottom third of fitted transfer fees with respect to actual ones is $+3 \%$ ( $+5 \%$ for the bottom fifth). This gap is $+1 \% \%$ for the top third of estimates $(+6 \%$ for the top fifth), while it is $-5 \%$ for the intermediate third of estimated values.

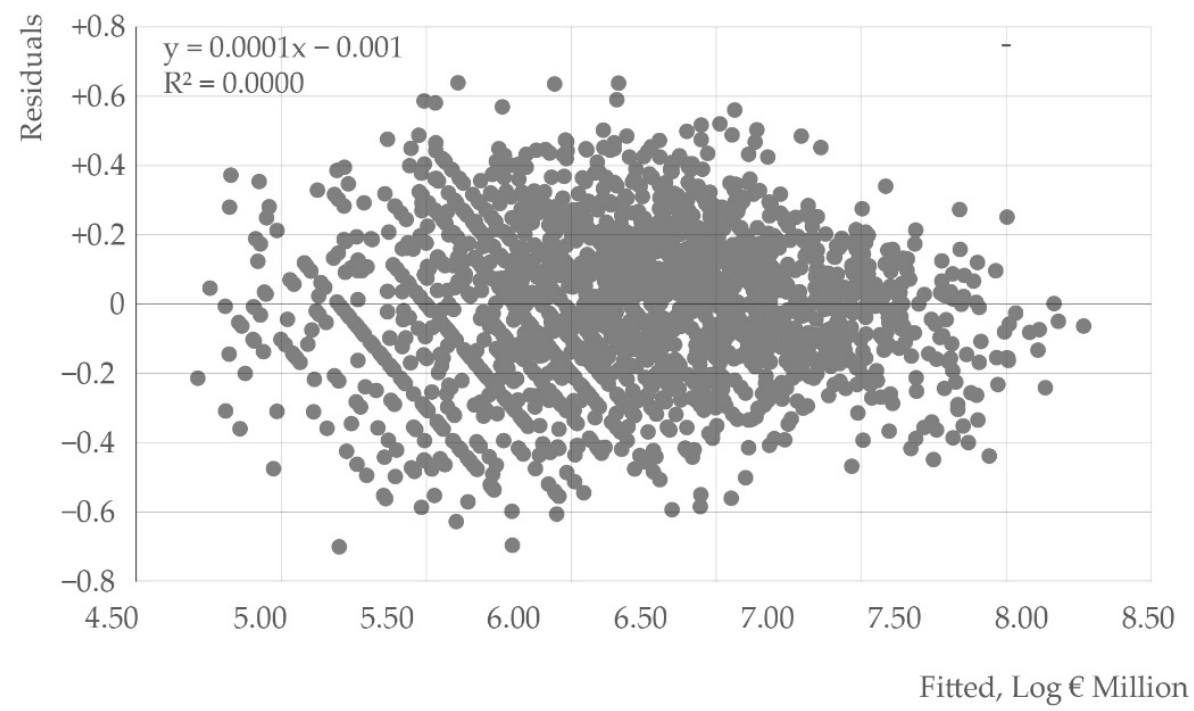

Figure 3. Residuals and fitted transfer fees.

Beyond explaining the transfer fees paid by clubs, it is possible to estimate transfer values prior to transfers using the same variables except that of the economic level of the recruiting club, which is in this case unknown. While also robust, the level of significance of this predictive model is slightly less than that used to explain transfer fees. This indicates that in a very polarized economic context (UEFA 2020; Deloitte 2020), as notably also highlighted by Dobson and Gerrard (1999) and Garcia del Barrio and Pujol (2021), prices on the football players' transfer market depend on the buyer: all other things being equal, a richer club will have to invest more money to convince the clubs owning the transfer rights of the desired player to release him.

Table 5 shows that the findings for the model built to assess fees remain valid for the model built to predict them. All variables selected are again significant. Contract length, age and experience are still the most important player-related elements. 
Table 5. Multiple linear regression model to predict transfer fees.

\begin{tabular}{|c|c|c|c|c|c|}
\hline \multicolumn{2}{|c|}{ Number of observations } & 2045 & & & \\
\hline \multicolumn{2}{|c|}{$\mathrm{F}(15,2029)$} & 569.19 & & & \\
\hline \multicolumn{2}{|c|}{ Prob > F } & 0 & & & \\
\hline \multicolumn{2}{|c|}{ R-squared } & $80.8 \%$ & & & \\
\hline \multicolumn{2}{|c|}{ Adj R-squared } & $80.7 \%$ & & & \\
\hline \multicolumn{2}{|c|}{ Root MSE } & 0.253 & & & \\
\hline Source & SS & df & MS & & \\
\hline Model & 548.4 & 15 & 36.56 & & \\
\hline Residual & 130.3 & 2029 & 0.06 & & \\
\hline Total & 678.7 & 2044 & 0.33 & & \\
\hline variable & b-coeff. & stand. beta & $\mathbf{t}$ & $p>t$ & sign \\
\hline contract & 0.524 & 0.227 & 21.3 & 0.000 & $* * *$ \\
\hline age & -0.063 & -0.386 & -32.5 & 0.000 & $* * *$ \\
\hline exp_gk & 0.779 & 0.568 & 37.9 & 0.000 & $* * *$ \\
\hline exp_cb & 0.672 & 0.982 & 34.5 & 0.000 & $* * *$ \\
\hline exp_fb & 0.612 & 0.825 & 32.1 & 0.000 & $* * *$ \\
\hline exp_md & 0.631 & 1.025 & 30.4 & 0.000 & $* * *$ \\
\hline exp_of & 0.603 & 1.179 & 27.4 & 0.000 & $* * *$ \\
\hline dynpro & 0.466 & 0.122 & 10.5 & 0.000 & $* * *$ \\
\hline dynreg & 0.249 & 0.049 & 4.4 & 0.000 & $* * *$ \\
\hline goal & 0.210 & 0.276 & 14.5 & 0.000 & $* * *$ \\
\hline assist & 0.113 & 0.079 & 5.9 & 0.000 & $* * *$ \\
\hline pass & 0.003 & 0.074 & 4.6 & 0.000 & $* * *$ \\
\hline dribble & 0.038 & 0.064 & 4.7 & 0.000 & $* * *$ \\
\hline ateam & 0.002 & 0.072 & 6.6 & 0.000 & $* * *$ \\
\hline inflat & 1.175 & 0.277 & 27.3 & 0.000 & $* * *$ \\
\hline _cons & 3.405 & . & 32.2 & 0.000 & $* * *$ \\
\hline
\end{tabular}

Although the coefficient of determination is lower than in the model including the recruiting club (around $80 \%$ ), a cross-validation analysis as displayed in Table 6 below confirms the high predictive power and robustness of this model too.

Table 6. 5-fold cross-validation analysis for model to predict transfer fees.

\begin{tabular}{lcccc}
\hline & \multicolumn{2}{c}{ Training Sample } & \multicolumn{2}{c}{ Test Sample } \\
& N & r2_adj & N & r2_adj \\
\hline Cross-validation 1 & 1636 & $81.0 \%$ & 409 & $78.9 \%$ \\
Cross-validation 2 & 1636 & $80.3 \%$ & 409 & $81.9 \%$ \\
Cross-validation 3 & 1636 & $80.7 \%$ & 409 & $80.2 \%$ \\
Cross-validation 4 & 1636 & $80.6 \%$ & 409 & $80.5 \%$ \\
Cross-validation 5 & 1636 & $80.7 \%$ & 409 & $80.4 \%$ \\
\hline
\end{tabular}

The application of the model to players from the five major European leagues on 1 December 2021 allowed us to identify up to twenty footballers with an estimated value of more than EUR 100M million. Among them, only the Portuguese player Bruno Fernandes from Manchester United was over 25 years old, with the average age of these twenty players being just about 22 years old. Moreover, all of the twenty players had at least two and half years of contract remaining with their employer club, and sixteen out of the twenty had a contract valid for at least three and a half years. 


\section{Discussion}

Despite their robustness, the econometric models developed, and more generally the typical approach used to build them, include some weaknesses. Firstly, the lack of transparency in the football industry means that not all of the data used, notably those on transfer fees, are certified. While a good level of accuracy can nevertheless be reached, the access to official data with all details, in particular regarding add-on and sell-on fees, would be a real plus for future research in this area.

An additional limit consists of the nature of the approach itself. Econometric modelling is only possible with data that are quantifiable on a large scale. This prevents us from including in the approach specific aspects that only concern a few players or clubs, or which are simply not quantifiable. Among these aspects, we can notably quote a club's particular economic situation (urgent need for cash, etc.), a disagreement between a player and his coach or fellow team members, the planned recruitment by a team of another footballer who plays in the same position of the player to be released, disciplinary concerns, physical problems that will affect future performance, the superstar effect for very popular players (Franck and Nüsch 2012; Lucifora and Simmons 2003), soft skills such as charisma and leadership, etc.

These and other specific elements considered by market actors during transfer negotiations can explain some of the discrepancies observed between fees predicted and actually paid. However, the high level of significance and robustness of the econometric models developed confirms the validity of the approach for the majority of players. Despite these limits, the development of a statistical model to assess transfer fees and evaluate transfer values on a scientific basis as described in this paper has thus a wide range of uses for market actors. A non-exhaustive list of tasks already performed by the authors is presented below.

\subsection{Negotiating Player Transfers}

The transfer market for football players takes place in an extremely speculative context where fake information is often leaked by clubs, intermediaries and the various media involved (Fürész and Rappai 2020). Market actors thus prefer to rely on objective valuations before starting any transfer negotiation. The approach developed also allows them to estimate specific prices for different potential buyers. Moreover, by means of such an econometric model, it is possible to project future values according to different scenarios, which is of great usefulness in particular concerning the negotiation of sell-on percentages and add-on fees.

\subsection{Negotiating Player Contracts}

As stated above, the algorithm developed allows market actors to forecast likely scenarios regarding the future transfer values of players according to their age, individual performance, club results, etc. These projections can be notably used by club officials to define fair remuneration levels for players without involving excessive risk, in choosing the best possible duration of a new contract or in determining a fair amount of an eventual buy-out clause.

\subsection{Transfer Litigation}

A scientific approach to determine transfer fees is also highly suited to situations of litigation over transfer amounts. The independent and objective expertise provided by an econometric model is notably useful to define a fair indemnity fee for former clubs in the case of a unilateral breach of contract on a player's part, as well as when previous clubs or players themselves held economic rights on transfers concluded for dubious amounts or without clear information on this matter. Swap deals also generate disputes for which scientific expertise is requested. Indeed, sell-on fees and solidarity contributions as provided for in FIFA's Regulations on the Status and Transfer of Players (FIFA 2021) 
also apply when players are exchanged. This seeks to define fair values for each player involved, even when no money was paid for the transaction.

\subsection{Negotiating Credits}

A scientific estimate of transfer values is also useful for clubs to obtain credits. Indeed, such a valuation constitutes a reliable indicator to assess clubs' creditworthiness. This is not necessarily the case when the latter is based on a player's book value (Amir and Livne 2005), as the real worth of players on the transfer market often deviates from that registered in the books. This is notably the case for players promoted from the club's youth academy (i.e., Marcus Rashford at Manchester United) and other players in the first team squad signed for free (i.e., Gianluigi Donnarumma at Paris St-Germain) or, in the opposite direction, for footballers signed for a great transfer fee who did not perform as expected (i.e., Philippe Coutinho at Barcelona).

\subsection{Financial Planning and Communication}

An objective valuation of the squad is also useful from a financial planning and communication perspective. Indeed, from a financial planning standpoint, many clubs depend on incomes generated on the transfer market to balance their books. A close monitoring of the estimated transfer values of players in their squad and the elaboration of possible scenarios in view of future transfer windows are of crucial importance to optimize operations. Estimated values calculated on a scientific basis by an independent body external to the club are also useful from a financial communication perspective, especially with regard to shareholders and the stock market for clubs listed.

\subsection{Taking Out Insurance}

With the increase in transfer costs, clubs and other parties holding players' transfer rights have started to take out insurance policies covering the possibility of the loss of value of a player, notably through injury. An econometric model such as that described in this paper allows all parties involved to define a fair amount to be insured and elaborate different scenarios to mitigate risks. A transfer value econometric model also allows the parties to monitor with accuracy the evolution in players' values and adapting insurance policies.

\subsection{Club Sale or Purchase}

For most of the teams worldwide, players are a major asset. A scientific and independent assessment of the overall transfer value of squad members, as well as the fee-paying transfer probability for individual players, are crucial factors to be taken into consideration when it comes to dealing with the purchasing or the selling of a player by a club. In addition, the objective assessment of players' transfer values is useful within the framework of clubs' bankruptcy procedures to liquidate assets or negotiate a take-over.

Author Contributions: Conceptualization, R.P.; Data curation, R.B. and L.R.; Formal analysis, R.B.; Investigation, R.P. and R.B.; Methodology, R.B.; Project administration, R.P.; Resources, L.R.; Supervision, L.R.; Validation, L.R.; Writing—original draft, R.P.; Writing—review \& editing, R.P. and R.B. All authors have read and agreed to the published version of the manuscript.

Funding: This research received no external funding.

Acknowledgments: The authors warmly thank the CIES direction and colleagues for their continuous support over the years.

Conflicts of Interest: The authors declare no conflict of interest. 


\section{References}

Amir, Eli, and Gilad Livne. 2005. Accounting, Valuation and Duration of Football Player Contracts. Journal of Business Finance E Accounting 32: 549-86. [CrossRef]

Antonioni, Peter, and John Cubbin. 2000. The Bosman Ruling and the Emergence of a Single Market in Soccer Talent. European Journal of Law and Economics 9: 157-73. [CrossRef]

Carmichael, Fiona, and Dennis Thomas. 1993. Bargaining in the Transfer Market: Theory and Evidence. Applied Economics 25: 1467-76. [CrossRef]

Carmichael, Fiona, David Forrest, and Robert Simmons. 1999. The Labour Market in Association Football: Who Gets Transferred and For How Much? Bulletin of Economic Research 51: 125-50. [CrossRef]

Coates, Dennis, and Petr Parshakov. 2021. The wisdom of crowds and transfer market values. European Journal of Operational Research, in press. [CrossRef]

Deloitte. 2020. Annual Review of Football Finance. Manchester: Deloitte.

Dobson, Stephen, and Bill Gerrard. 1999. The determination of player transfer fees in English professional soccer. Journal of Sport Management 13: 259-79. [CrossRef]

Dobson, Stephen, Bill Gerrard, and Simon Howe. 2000. The determination of transfer fees in English non-league football. Applied Economics 32: 1145-52. [CrossRef]

Felipe, José Luis, Alvaro Fernandez-Luna, Pablo Burillo, Luis Eduardo de la Riva, Javier Sanchez-Sanchez, and Jorge Arciaa-Unanue. 2020. Money Talks: Team Variables and Player Positions that Most Influence the Market Value of Professional Male Footballers in Europe. Sustainability 12: 3709. [CrossRef]

FIFA. 2015. Regulations on Working with Intermediaries. Zurich: FIFA. Available online: https://digitalhub.fifa.com/m/352df54820ee1a5 9/original/cr6dquxm2adupv8q3ply-pdf.pdf (accessed on 20 December 2021).

FIFA. 2021. Regulations on the Status and Transfer of Players. Zurich: FIFA. Available online: https://digitalhub.fifa.com/m/e7a6c038 1ba30235/original/g1ohngu7qdbxyo7kc38e-pdf.pdf (accessed on 20 December 2021).

FIFA TMS. 2020. Global Transfer Market Report 2020. A Review of International Football Transfers Worldwide. Zurich: FIFA. Available online: https://digitalhub.fifa.com/m/c54634f8bb5a641d/original/ijiz9rtpkfnbhxwbqr70-pdf.pdf (accessed on 20 December 2021).

Franck, Egon, and Stephan Nüsch. 2012. Talent and/or popularity: What does it take to be a superstar? Economic Inquiry 50: 202-16. [CrossRef]

Fürész, Diána I., and Gábor Rappai. 2020. Information leakage in the football transfer market. European Sport Management Quarterly 1-21. [CrossRef]

Garcia del Barrio, Pedro, and Francesc Pujol. 2021. Recruiting talent in a global sports market: Appraisals of soccer players' transfer fees. Managerial Finance 47: 789-811. [CrossRef]

He, Miao, Ricardo Cachucho, and Arno Knobbe. 2015. Football Player's Performance and Market Value. In Proceedings of the 2nd Workshop on Machine Learning and Data Mining for Sports Analytics. Edited by Jesse Davis, Jan van Haaren and Albrecht Zimmermann. Aachen: CEUR-WS, pp. 87-95.

Herm, Steffen, Hans-Markus Callsen-Bracker, and Henning Kreis. 2014. When the crowd evaluates soccer players' market values: Accuracy and evaluation attributes of an online community. Sport Management Review 17: 484-92. [CrossRef]

Kirschstein, Thomas, and Steffen Liebscher. 2019. Assessing the market values of soccer players-A robust analysis of data from German 1. and 2. Bundesliga. Journal of Applied Statistics 46: 1336-49. [CrossRef]

Lucifora, Claudio, and Robert Simmons. 2003. Superstar Effects in Sport: Evidence from Italian Soccer. Journal of Sports Economics 4: 35-55. [CrossRef]

Majewski, Sebastian. 2016. Identification of Factors Determining Market Value of the Most Valuable Football Players. Journal of Management and Business Administration 24: 91-104. [CrossRef]

Müller, Oliver, Alexander Simons, and Alexander Weinmann. 2017. Beyond Crowd Judgments: Data-Driven Estimation of Market Value in Association Football European. Journal of Operational Research 263: 611-24. [CrossRef]

Poli, Raffaele. 2009. Agents and intermediaries. In Managing Football: An International Perspective. Edited by Simon Chadwick and Sean Hamil. London: Elsevier, pp. 201-16.

Poli, Raffaele, Roger Besson, and Loïc Ravenel. 2020. The Real Impact of COVID on the Football Players' Transfer Market. Neuchâtel: CIES. Available online: https:/ / football-observatory.com/IMG/sites/mr/mr58/en/ (accessed on 20 December 2021).

Prockl, Franziska, and Bernd Frick. 2018. Information Precision in Online Communities: Player Valuations on www.Transfermarkt.de. International Journal of Sport Finance 13: 319-35.

Romann, Michael, Marie Javet, Stephen Cobley, and Dennis-Peter Born. 2021. How Relative Age Effect Associate with Football Players' Market Values. Sports 9: 99. [CrossRef]

Ruijg, Jeroen, and Hans van Ophem. 2015. Determinants of football transfers. Applied Economics Letter 22: 12-19. [CrossRef]

Serna Rodríguez, Maribel, Andrés Ramírez Hassan, and Alexander Coad. 2018. Uncovering Value Drivers of High Performance Soccer Players. Journal of Sports Economics 20: 1-31. [CrossRef]

Singh, Prabhnoor, and Puneet Singh Lamba. 2019. Influence of crowdsourcing, popularity and previous year statistics in market value estimation of football players. Journal of Discrete Mathematical Sciences and Cryptography 22: 113-26. [CrossRef] 
UEFA. 2020. The European Club Footballing Landscape. Nyon: UEFA. Available online: https://www.uefa.com/MultimediaFiles/ Download/OfficialDocument/uefaorg/Clublicensing/02/64/06/95/2640695_DOWNLOAD.pdf (accessed on 20 December 2021).

Velema, Thijs A. 2018. Upward and downward job mobility and player market values in contemporary European professional football. Sport Management Review 22: 209-21. [CrossRef]

Wicker, Pamela, and Daniel Weimar. 2017. Moneyball Revisited: Effort and Team Performance in Professional Soccer. Journal of Sports Economics 18: 140-61. [CrossRef] 